Bayero Journal of Pure and Applied Sciences, 5(2): 84 - 88

Received: September 2012

Accepted: November 2012

ISSN $2006-6996$

\title{
DETECTION OF METALLO BETALACTAMASES AMONG GRAM NEGATIVE BACTERIAL ISOLATES FROM MURTALA MUHAMMAD SPECIALIST HOSPITAL, KANO AND ALMADINA HOSPITAL KADUNA, NIGERIA
}

\author{
*Yusuf, $\mathbf{I}^{1}$., Yusha'u, $\mathbf{M}^{1}$., Sharif, A. A $^{2}$., Getso, M $^{2}$. I., Yahaya, H $^{3}$, Bala, J. A ${ }^{3}$., Aliyu I. A ${ }^{3}$. \\ and Haruna, $\mathrm{M}^{4}$ \\ ${ }^{1}$ Department of Microbiology, Faculty of Science, Bayero University, P.M.B 3011, Kano-Nigeria \\ ${ }^{2}$ Department of Medical Microbiology and Parasitology, Faculty of Medicine, Bayero University, P.M.B 3011, Kano- \\ Nigeria \\ ${ }^{3}$ Department of Medical Laboratory Science, Faculty of Science, Bayero University, P.M.B. 3011, Kano, Nigeria \\ ${ }^{4}$ Department of Biology, Kano University of Science and Technology, Wudil, Kano, Nigeria \\ *correspondence author: yusufi4730@buk.edu.ng
}

\begin{abstract}
Over the last few years, the increase in the number of multi-resistant (MR) enterobacteria has become a major clinical problem. This study detects the occurrence and prevalence of Metallo betalactamase production among some clinical bacterial isolates in Murtala Muhammad Specialist Hospital, Kano and Al-Madina Specialist Hospital Kaduna, Nigeria. A total of 200 clinical isolates comprising of E. coli (83), Klebsiella pneumoniae (52), Pseusomonas aeruginosa (28) and Proteus mirabilis (37) were screened phenotypically for carbapenemase and specifically for Metallo betalactamase using Modified Hodges Test and EDTA DisC Synergy Test respectively. The result showed that $67(33.5 \%)$ of the isolates were found to produce carbapenemase. High production occurred in 24(35.8\%) and low production occurred in 43(64.2\%) of the isolates. Highest prevalence of carbapenemase was found in Pseudomonas aeruginosa (38.55\%) followed by $E$. coli (34.8\%), Proteus mirabilis. (29.1\%) and least prevalence in Klebsiella pneumoniae (25.0\%). The prevalence of MBLs in the study was $24.5 \%$ with highest prevalence in E. coli (31.32\%) followed by Proteus mirabilis. (21.6\%), Pseudomonas aeruginosa (21.2\%) and least among Klebsiella pneumoniae. (14.3\%). Most of carbapenemase producers produce MBL type. Urine samples were found to be with the highest prevalence of 38.3\% when compared with ear swab (12.0\%). Prevalence of $67.9 \%$ and $76.9 \%$ were recorded for Murtala Muhammad specialist hospital Kano and Al-madina hospital Kaduna respectively. This showed that carbapenemase-mediated resistance occurred in the selected hospitals and uncontrolled spread may lead to treatment failure and frustration.
\end{abstract}

Keywords: Metallobetalactamase, Carbapenemase, Enterobacteriaceae, prevalence, Hospital

\section{INTRODUCTION}

Beta-lactam antibiotics are widely used antibiotics in the treatment and management of infectious bacteria in Nigerian hospitals (Yusuf and Arzai, 2011). However, the production of single spectrum betalactamases, one of the resistance mechanisms encountered in Enterobacteriaceae, mainly E. coli and $K$. pneumoniae, has been associated with several treatment failures when one or more of the antibiotics are used.

Carbapenemase enzymes belonging to Ambler molecular classes $A$ to $D$ have been detected in various clinical isolates in Nigeria (Yusuf et al., 2011). Metallo-beta-lactamases enzymes, whose genes are plasmid and integron located, hydrolyze virtually all Beta-Lactams except aztreonam (Walsh, 2008). Many of the carbapenemase producers are frequently resistant to flouroquinolones and aminoglycosides (Heffernan et al., 2006). One strategy developed by bacteria to resist action of betalactam antibiotics is the expression of Metallo-Betalactamases requiring Zinc $\left(\mathrm{Zn}^{2+}\right)$ for activity (Heffernan et al., 2006). Metallo-beta-lactameses is an enzyme that confers antibiotic resistance to Bacteria by catalyzing the hydrolysis of Beta-lactam antibiotics
(Yong et al., 2009). Different enzymes of MBLs have been identified which are the IMP type Carbapenemases, VIM (Verona Integron-encoded Metallo-Beta-lactamase) and the NDM-1 (New Delhi MBLs).

Among Enterobacteriaceae, resistance to carbapenemase is still rare and the awareness of its occurrence and effects is low especially in Nigerian hospitals.

Metallo-Beta-Lactamases mediated resistance is a course for concern in the therapy of clinically ill patient. The relatively new form of resistance is spreading unchallengeable as there is a current lack of potent and selective inhibitors of MBLs. Spread of MBLs deserves a study in real time of how resistance can become global. Their rapid dissemination is worrisome and necessitates not just surveillance study but also studying occurrence and prevalence in a hospital setting to formulate a policy of empirical therapy. The research therefore aim at detecting the occurrence and prevalence of MBLs among Enterobacteriaceae from Murtala Muhammad specialist hospital Kano and Almadina hospital Kaduna using phenotypic method. 


\section{MATERIALS AND METHODS}

Sample Collection

\section{a) Clinical Isolates}

A total of 200 clinical isolates of members of the family Enterobacteriaceae were collected from pathology department of Murtala Muhammad Specialist Hospital Kano and Almadina Hospital Kaduna. Isolates were collected along with information on the sample type, hospital number, age and sex of the patients.

\section{b) Control Strain}

$E$.coli ATCC 25922 was used as control and was collected from Aminu Kano Teaching Hospital

\section{Screening of pathogen for Carbapenemase Production}

Modified Hodges Test was adopted as described by Walsh et al. (2011) and CLSI (2009).

A 0.5 McFarland suspension of the control E. coli ATCC 25922 was inoculated on a well dried Muiller Hinton Agar (MHA) (Oxoid, UK) using a sterile wire loop.

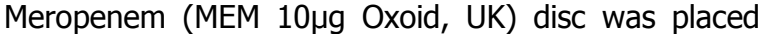
using a sterile forceps on the surface at the middle of the MHA plate. In a straight line, the test organism was streaked from the edge of the MEM disc to the edge of the culture plate. The plates were incubated for $24 \mathrm{hrs}$ at $37^{\circ} \mathrm{C}$. After $24 \mathrm{hrs}$ of incubation, the plates were examined for flattening and indentation at the intersect of the organism and E. coli ATCC 25922 within the zone of inhibition of the MEM susceptibility disc as described by Clinical laboratory standard institute (2009).

\section{Inhibitory Based Test for MBLs}

EDTA-disc synergy test or combined disc test was used as described by Walsh et al., 2011 and CLSI (2009). A carbapenemase producing isolate was streaked on the surface of the MHA (Oxoid UK) using a sterile wire loop. Two meropenem (MEM) (10 $\mathrm{gg}$ Oxoid UK) discs, one containing EDTA and the other without EDTA were placed on the surface of the MHA using a sterile forceps at a distance of about $30 \mathrm{~mm}$ apart. The plates were incubated for $24 \mathrm{hrs}$ at $37^{\circ} \mathrm{C}$. Zones of inhibition were recorded after $24 \mathrm{hrs}$ of incubation. Organisms that showed difference in diameter of zone of inhibition by $\geq 4 \mathrm{~mm}$ on the MEM containing EDTA and MEM alone were confirmed for the production of MBLs.

\section{RESULTS}

Out of the total 200 isolates screened, 67(33.5\%) were found to produce carbapenemase. Highest prevalence of carbapenemase was found among Pseudomonas aeruginosa (38.55\%) followed by $E$. coli (34.8\%), Proteus mirabilis (29.1\%) and least prevalence in Klebsiella pneumoniae. (25.0\%) (Table1). Of the carbapenemase producers, $24(35.8 \%)$ were found to produce strong carbapenemase with indented zones and 43(64.2\%) produces a weak type of the enzymes with flattened zones. (Table 2). The prevalence of MBLs in the study was $24.5 \%$ (Table 3 ), highest prevalence was recorded among $E$. coli $(31.32 \%)$ followed by $P$. mirabilis $(21.6 \%), P$. aeruginosa $(21.2 \%)$ and least among $K$. pneumoniae (14.3\%) (Table 3 ). Based on clinical samples, urine was found with high prevalence of MBLs (38.3\%), followed by wound swab (30.9\%), semen and sputum (25.0\%) (Table 5 ).

While distribution of MBLs based on sex recorded $26.9 \%$ and $23.3 \%$ among male and female respectively, the distribution of MBLs according to Hospital, recorded a prevalence of MBLs was $67.9 \%$ and $76.9 \%$ in Murtala Muhammed specialist hospital Kano and Al-madina hospital Kaduna respectively (Table 6).

Table 1: Occurrence of Carbapenemase among the Clinical bacterial Isolates

\begin{tabular}{lccc}
\hline Clinical Isolates & $\begin{array}{c}\text { Total Number of } \\
\text { Isolates } \\
\text { screened }\end{array}$ & $\begin{array}{c}\text { Number of } \\
\text { Isolates } \\
\text { producing } \\
\text { carbapenemase }\end{array}$ & \% Prevalence \\
\hline E. coli & 83 & 29 & 34.9 \\
P. aeruginosa & 52 & 20 & 38.5 \\
K. pneumoniae & 28 & 7 & 25.0 \\
P. mirabilis & 37 & 11 & 29.7 \\
\hline Total & $\mathbf{2 0 0}$ & $\mathbf{6 7}$ & $\mathbf{3 3 . 5}$ \\
\hline
\end{tabular}

Table 2: Strength of carbapenemase produced by the isolates based on indentation and flattening of zone of inhibition

\begin{tabular}{lccc}
\hline Clinical Isolates & $\begin{array}{c}\text { carbapenemase } \\
\text { Positive }\end{array}$ & Strong AmpC & Weak AmpC \\
\hline E. coli & 29 & $10(34.5)$ & $19(65.5)$ \\
P. aeruginosa & 20 & $6(30.0)$ & $14(70.0)$ \\
K. pneumoniae & 07 & $3(42.9)$ & $4(57.1)$ \\
P. mirabilis & 11 & $5(45.5)$ & $6(54.5)$ \\
\hline Total & $\mathbf{6 7}$ & $\mathbf{2 4 ( 3 5 . 8 )}$ & $\mathbf{4 3 ( 6 4 . 2 )}$ \\
\hline
\end{tabular}

Figures in parenthesis are percentages 
Table 3: Occurrence of MBLs among the Isolates using EDTA-disc synergy test

\begin{tabular}{llccc}
\hline S/N & Clinical isolates & $\begin{array}{c}\text { Total No. of Isolates } \\
\text { screened }\end{array}$ & $\begin{array}{c}\text { No. of Isolates } \\
\text { producing MBLs }\end{array}$ & \% prevalence \\
\hline 1 & E. coli & 83 & 26 & 31.3 \\
2 & P. aeruginosa & 52 & 11 & 21.2 \\
3 & K. pneumoniae & 28 & 4 & 14.3 \\
4 & P. mirabilis & 37 & 8 & 21.6 \\
\hline & Total & $\mathbf{6 7}$ & $\mathbf{4 9}$ & $\mathbf{2 4 . 5}$ \\
\hline
\end{tabular}

Table 4: Occurrence of MBLs among Carbapenemase producing Bacteria

\begin{tabular}{lllll}
\hline $\mathbf{S} / \mathbf{N}$ & Clinical isolates & $\begin{array}{l}\text { No. of isolates } \\
\text { producing } \\
\text { carbapenemase }\end{array}$ & $\begin{array}{l}\text { No. of isolates } \\
\text { producing MBLs }\end{array}$ & \%revalence \\
\hline 1 & E. coli & 29 & 26 & 89.7 \\
2 & P. aeruginosa & 20 & 11 & 55.0 \\
3 & K. pneumoniae & 7 & 4 & 57.1 \\
4 & P. mirabilis & 11 & 8 & 72.7 \\
\hline
\end{tabular}

Table 5: Distribution of MBLs producing isolates based on Sex of patients

\begin{tabular}{llcc}
\hline Sex & $\begin{array}{l}\text { No of isolates } \\
\text { Screened }\end{array}$ & Positive MBLs & \% prevalence \\
\hline Male & 63 & 17 & 26.9 \\
Female & 137 & 32 & 23.3 \\
\hline Total & $\mathbf{2 0 0}$ & $\mathbf{4 9}$ & $\mathbf{4 9 . 2}$ \\
\hline
\end{tabular}

Table 6: Prevalence of MBLs among clinical samples

\begin{tabular}{llccc}
\hline S/N & Clinical samples & $\begin{array}{c}\text { No. of Isolates } \\
\text { screened }\end{array}$ & $\begin{array}{c}\text { No. of Isolates } \\
\text { producing MBLs }\end{array}$ & \% prevalence \\
\hline 1 & Urine & 47 & 18 & 38.3 \\
2 & Stool & 30 & 5 & 16.7 \\
3 & High vaginal swab & 43 & 9 & 20.9 \\
4 & Ear Swab & 25 & 3 & 12.0 \\
5 & Wound Swab & 10 & 3 & 30.0 \\
6 & Semen & 20 & 5 & 25.0 \\
7 & Sputum & 16 & 4 & 25.0 \\
8 & Blood culture & 9 & 2 & 22.2 \\
\hline \multicolumn{1}{r}{ Total } & & $\mathbf{2 0 0}$ & $\mathbf{4 9}$ & $\mathbf{2 4 . 5}$ \\
\hline
\end{tabular}

Table 7: Distribution of MBLs production based on Hospitals Murtala Muhammad Specialist Hospital

Almadina Hospital

\begin{tabular}{|c|c|c|c|c|c|c|c|}
\hline $\mathbf{S} / \mathbf{N}$ & $\begin{array}{l}\text { Clinical } \\
\text { Isolates }\end{array}$ & No. & $\begin{array}{l}\text { No. producing } \\
\text { carbapenemase } \\
(\%)\end{array}$ & $\begin{array}{l}\text { No. } \\
\text { Producing } \\
\text { MBLs (\%) }\end{array}$ & No. & $\begin{array}{l}\text { No. producing } \\
\text { carbapenemase } \\
(\%)\end{array}$ & $\begin{array}{l}\text { No. } \\
\text { producing } \\
\text { MBLs (\%) }\end{array}$ \\
\hline 1 & E. coli & 21 & $7(33.3)$ & $6(85.7)$ & 52 & $22(42.3)$ & $20(90.9)$ \\
\hline 2 & $\begin{array}{l}P . \\
\text { aeruginosa }\end{array}$ & 32 & $8(25.0)$ & $4(50.0)$ & 25 & $12(58.3)$ & $7(58.3)$ \\
\hline 3 & $\begin{array}{l}K \\
\text { pneumoniae }\end{array}$ & 18 & $4(22.2)$ & $2(50.0)$ & 11 & $3(66.7)$ & $2(66.7)$ \\
\hline 4 & P. mirabilis & 27 & $9(33.3)$ & $7(77.8)$ & 14 & $2(50.0)$ & $1(50.0)$ \\
\hline & Total & 98 & $28(28.6)$ & 19(67.9) & 102 & $39(38.2)$ & $30(76.9)$ \\
\hline
\end{tabular}

\section{DISCUSSION}

The first report of carbapenemase detection among clinical bacterial pathogens in Kano was in 2010 (Yusuf and Arzai, 2011). The prevalence of $14.0 \%$ was reported. Few months later another research published by Yusuf et al., (2011) reported a prevalence of $13.32 \%$ in Kano Nigeria. In comparison with current study, the prevalence is high. This shows that the carbapenemase resistance is on rapid increase in Kano. This may be as a result of unawareness of their occurrence, effects but only the consequences is being felt as a number of treatment failures have been reported when antibiotics such as cephalosporins, penicillins, quinolones are used. A higher prevalences were reported elsewhere for example Bush, (1998) also reported 59\% in New York. This high difference in prevalence could be due as a result of unavailability and cost of the antibiotics here where only few can afford to buy it. 
The high prevalence among $E$. coli and $P$. aeruginosa is of clinical important as these species are among the most frequent Gram-negative bacteria involved in hospital-acquired infections and nosocomial outbreaks worldwide (Coque et al., 2002). In addition, $P$. aeruginosa, which is a bacterium commonly implicated in nosocomial infections with highest prevalence of (38.5\%) is currently one of the most antibiotic resistant organisms known. It exhibits resistance by the use of translocases (efflux pump), and decreased porin transport. They have metabolic versatibility/biochemical omnipotence i.e. ability to breakdown a wide spectrum of substrates (including disinfectants, dyes, antibiotics, antiseptics, salts) and ability to grow without organic growth factors.

Out of the carbapenemase producers, $24(35.8 \%)$ were found to produce strong carbapenemase with indented zones and 43(64.2\%) produces a weak type of the enzymes with flattened zones. This showed that most of the enzymes produced by the isolates studied are strong type capable of rendering antibiotics useless faster.

The prevalence of MBLs in the study was 24.5\%. Highest prevalence was recorded among $E$. coli $(31.32 \%)$ followed by $P$. mirabilis $(21.6 \%), P$. aeruginosa $(21.2 \%)$ and least among $K$. pneumoniae $(14.3 \%)$. MBLs are a type of carbapenemase requiring Zinc $^{+}$for activity. This coincides with other findings in Taiwan reporting higher prevalence in $E$. coli with $36.9 \%$ (Walsh et al., 2011), 28.6\% in Brazil (Bryce et al., 2000) and $26.4 \%$ in Spain (Kollef et al., 2007). This gradual increase could be as a result of self medication with antibiotics which are rampant in these parts of the countries or as a result of poor hygiene among medical personnel that leads to their uncontrolled spread.

However, majority of carbapenemase producers in this study (73.1\%) produces MBLs type. Highest of such was found in $E$. coli $(89.7 \%)$ and least prevalence was recorded for Pseudomonas aeruginosa (55.0\%). An earlier study by Desphande et al., 2010 also revealed higher production of MBLs from carbapenemase producing organisms which was $91.7 \%$. This indicated that these clinical pathogens will hydrolyze virtually all Beta-lactams except aztreonam used in the treatment of the infection they caused (Walsh, 2008). In addition, many of the carbapenemase producers are frequently resistant to flouroquinolones and aminoglycosides (Heffernan et al., 2006). This will result in outright delay in recovery and delays the admission of new patients requiring urgent attention into wards thereby causing havoc between the patients and the clinicians. Because this carbapenemase is encoded on plasmids that may jump from bacteria to bacteria easily facilitating rapid

\section{REFERENCES}

Bryce, E.A., Tiffin, S.M., Isaac-Renton, J.L., and Wright, C.J. (2000): Simple microdilution test for detection of metallo-beta-lactamase production in Pseudomonas aeruginosa. $J$ Clin Microbiol. 40: 4388-4390.

Bush, K. (1998): Metallo-beta-lactamases: a class apart. Clin. Infect. Dis. 27(Suppl. 1):S48-S53. dissemination and spread between different bacterial species by lateral gene transfer favoured by globalization and travel represent a high risk of a worldwide pandemia among Enterobacteriaceae (Lee et al., 2007). Moreover, the spread poses a number of problems in the hospitals such as lack of a routine standardized phenotypic test for MBL detection, consequent probable high prevalence of unrecognized asymptomatic carriers, allowing an international dissemination of such bacteria, scarcity of available effective antibiotics so far, and the possibility to disseminate in many different Gram-negative bacteria.

Based on clinical samples, urine was found with high prevalence of MBLs (38.3\%), followed by wound swab (30.9\%), semen and sputum (25.0\%). Nordman et al., 2009 and Peirano, 2010 also reported higher MBLs production in urine as $27.0 \%$ and $30.0 \%$ in France and Australia respectively. Urinary tract infection is on increase worldwide and a multitude of antibiotic is used in their treatment. The reports of urinary pathogen's resistant to wide range of antibiotics in Kano, Nigeria mediated by extended spectrum beta Lactamases, AmpC beta lactamases and carbapenemases have been reported by Yushau et al., 2007; Yusuf et al., 2011 and Yusuf and Arzai, 2011 respectively. This may indicate that majority of the carbapenemase producing type reported earlier may be MBLs type. According to the distribution of MBLs based on sex, $26.9 \%$ and $23.3 \%$ were recorded among male and female respectively. Statistically the result shows no significant difference between them, that is MBLs infection is not sex dependent $(P \leq 0.05)$.

The distribution of MBLs according to Hospital, the prevalence of MBLs was $67.9 \%$ and $76.9 \%$ in Murtala Muhammed specialist hospital Kano and Almadina hospital Kaduna respectively. This difference could be as a result of patient related factors which are the major drivers of inappropriate use of antibiotics and the fact that such enzymes have not been reported in Kaduna, hence no awareness of their existence.

\section{CONCLUSION}

From the result obtained in this study, it is concluded that

a) Carbapenemases particularly MBLs occurred among clinical isolates in the two hospitals studied.

b) Majority of the carbapenemase producing isolates also produce MBLs.

c) MBLs production is not sex dependent but varies between hospitals.

d) Prevalence of MBLs was high among isolates from urine samples.

Cheesbrough M. (2002): District laboratory practices in tropical countries ( part 2 ). Cambridge Univ press. Pp. 77-140.

Clinical and Laboratory Standards Institute (2009): Performance standards for antimicrobial susceptibility testing; 19th informational supplement. CLSI document M100-S19. Wayne, PA: CLSI. 
Coque, T. M., Oliver, A., Pérez-Díaz, J.C., Baquero, F. and Cantón, R. (2002): Genes Encoding TEM4, SHV-2, and CTX-M-10 Extended-Spectrum$\beta$-Lactamases Are Carried by Multiple Klebsiella pneumoniae Clones in a Single Hospital (Madrid, 1989 to 2000). Antimicrob. Agents Chemother. 46(2): 500-509

Deshpande, P., Rodrigues C., Shetty A., Kapadia F., Hedge A. and Soman, R. (2010): "New Delhi Metallo-beta lactamase (NDM-1) in Enterobacteriaceae: Treatment options with Carbapenems Compromised". Journal of Association of Physicians of India; 58: 147150.

Heffernan, H., Woodhouse R. and Blackmore, T. (2006): Prevalence of extended-spectrum beta-lactamases among Escherichia coli and Klebsiella spp in New Zealand in 2006. Porirua: Institute of Environmental Science and Research

Kollef, M.H., Sherman, G., Ward, S. and Fraser, V.J. (2007): Inadequate antimicrobial treatment of infections: a risk factor for hospital mortality among critically ill patients. Chest.115:62-74.

Lee, K, Yong, D, Choi, Y.S., Yum, J.H., Kim, J.M., Woodford, N, Livermore, D.M., and Chong, Y. (2007): Reduced Imipenem susceptibility in Klebsiella pneumoniae clinical isolates with plasmid-mediated $\mathrm{CMY}-2$ and $\mathrm{DHA}=1$ beta lactamase co-mediated by porin loss. Int $J$ Antimicrob agents. 29:201-206

Nordmann, P., Cuzon, G. and Naas, T. (2009): "The real threat of Klebsiella pneumoniae carbapenemase-producing bacteria". Lancet Infect Dis. 9 (4): 28-36.

Peirano, G. (2010): High prevalence of ST131 isolates producing CTX-M-15 and CTX-M-14 among extended-spectrum-beta-lactamase-

producing Escherichia coli isolates from Canada. Antimicrob. Agents Chemother. 54: $1327-1330$

Walsh, T.R. (2008): Clinically significant carbapenemases: An update. Curr Opin Infect Dis. 21:367-71.

Walsh, T.R., Janis, W., David, M.L and Mark, A.T. (2011): "Dissemination of NDM-1 positive bacteria in the New Delhi environment and its implications for human health: an environmental point prevalence study". The Lancet Infectious Disease. 20:11-13.

Yong, D., Giske, C.G., Toleman, M. and Walsh, T.R. (2009): A novel subgroup metallo-betalactamase (MBL), NDM-1 emerges in Klebsiella pneumoniae (KPN) from India. 48th Annual ICAAC/IDSA 46th Annual Meeting, Washington DC; 5:87.

Yusha'u, M., Olonitola, S. O. and Aliyu, B. S. (2007): Prevalence of Extended - Spectrum Beta lactamases (ESBLs) Among members of the Enterobacteriaceae isolates obtained from Mohammed Abdullahi Wase Specialist Hospital, Kano, Nigeria. International Journal of Pure and Applied Sciences 1 (3): $42-48$

Yusuf, I, Haruna, M, Hamid, K.M., Muhammad, B, Jega, S.A. (2011): Detection of AmpC, Carbapenemase and Extended spectrum beta lactamases among clinical bacterial pathogens in Nigeria. Africa Journal of science, technology and social sciences $1(1): 8-24$

Yusuf, I. and Arzai, A.H. (2011): First Detection of Carbapenemases Producing Clinical Bacterial Pathogens in Kano, Nigeria. Biological and Environmental Sciences Journal for the Tropics 8(3): 163-167 